\title{
Multi-functioning in Virtual Monitoring of Thin-walled Bridges
}

\author{
Alexander Tesár \\ Institute of Construction and Architecture, Slovak Academy of Sciences, Dubravska cesta 9, \\ 84503 Bratislava 45, Slovak Republic \\ e-mail: usarate@savba.sk
}

\begin{abstract}
Multi-functioning in virtual monitoring of thin-walled bridges is treated in present paper. The approach enables multiple functions in virtual monitoring of bridges made of integrated thin-walled members with their hierarchical configuration. Theoretical, numerical and experimental in situ assessment of the problem is presented. Some results of structural application are submitted.
\end{abstract}

Key words: multi-functioning, optimization, thin-walled bridge, ultimate behavior, virtual monitoring, wave propagation

\section{Introduction}

Although human genius through various inventions makes instruments corresponding to the same ends, it will never discover an invention more beautiful nor more ready nor more economic than does nature, because in her inventions nothing is lacking and nothing is superfluous ([1]).

One of interesting features of natural organisms from a design point of view is the coexistence of multiple functions in a single component. Natural organisms are the set-ups with many sub-systems being integrated together. The nature contains countless elegant and highly multi-functioning systems that are of great relevance to human design. It is therefore very useful to study multi-functioning in nature because the results can be implemented into desirable attributes for design.

Such integration and multi-functioning appear also in virtual monitoring of slender thinwalled bridges used in present structural engineering. Thin-walled structures, generally, are the products based on the backgrounds of nature. During their development the engineers have adopted a design philosophy of integrating various design functions together. Some of the issues considered in their design are mentioned as follows:

Multi-function No. 1 - Optimal loading control 
The loads can be varied by suitable geometry and shape of thin-walled members adopted. For example, the wind turbulences produce a strong vortex wake associated with aerodynamic drag force experienced by thin-walled member. Depending on the wind speed and the crosssection's shape, the shedding of vortices is more or less regular with shedding periods inversely proportional to the wind speed. In resonant conditions thin-walled structure's oscillations control the rhythm of the vortex shedding appearing. Aside the known vortex trail type excitation the more general types of aerodynamic forcing appear there. Aeroelastic forces proportional to the movement of the structure result in self-induced divergent vibrations at high wind speeds. In design is to be avoided that absolute value of negative aerodynamic damping force exceeds the positive mechanical damping force producing oscillatory torsional or across-wind flexural mode instability.

Multi-function No. 2 - Optimal structural layout

The layout of thin-walled members in bridge is optimal for generating an efficient flow of forces. Besides an optimal layout thin-walled bridges also have optimal material and shape properties being structurally efficient for resisting loads.

Multi-function No. 3 - Optimal material layout

The shape is optimal for flexural strength because thin-walled sections place the material away from the neutral axis. The calculation considers the behavior of single member in a continuous contact with other members and the modeling takes into account all interactions possibly appearing.

Multi-function No. 4 - Optimal fail-safe mechanisms

Modern thin-walled structures are equipped with embedded self-healing mechanisms that are activated when a crack develops. The self-healing cells in connections of thin-walled members consist of interacting structural members being activated when the material is overstressed. The self-healing cells are small enough so that overall structural properties of the structure are not significantly compromised. The fail-safe mechanisms are adopted in their hierarchical configuration. If the elements are overloaded they will unzip from adjacent members before serious damages occur. Once unzipped, the elements can be re-zipped together by simple load and stress redistribution. The large number of separate zipping mechanisms ensures that the structure will unzip very close to the limit point of overload, thus causing minimum damage.

\section{Multi-function No. 5 - Tuned behaviour control}

New devices for tuned behavior control are also multi-functionally adopted in slender thinwalled bridges. For example, to ensure the satisfactory interaction between such materials as fiber composites, steel or concrete, the shear connectors have to be placed in the areas of concentrated load introduction. Such tuning facilities are adopted with regard to three main items as are the changes in stiffness, moment resistance and rotation capacity (ductility). Tuned vibration with control joints also contributes to multi-functioning in thin-walled bridges subjected to vibration forcing.

Some approaches dealing with multi-functioning in virtual monitoring of thin-walled bridges are considered in this paper. 


\section{Structural assesment}

The analysis is based on the the presumption of propagating waves with efficient exchange of potential and kinetic energy appearing. Thin-walled bridge is radiated by the waves initiated by traffic or load impacts and the response appearing is transmitted into all structural parts studied.

The wave propagation has two physical aspects - the source of waves and the medium where the waves are running. The waves initiated in the source are filtered during propagation in the bridge and are specified by spectral evolution. The diffraction of waves appears there in the inhomogeneities of the bridge studied.

The spectral evolution is based on following definitions:

1. Each stationary function $x(t)$ is interpreted in integral form by

$$
y(t)=\int \mathrm{e}^{\mathrm{i} \omega \mathrm{t}} \mathrm{dA}(\omega)
$$

with $A(\omega)$ as orthogonal complex process.

2. The linear transformation $y(t)$ of the function $x(t)$ is given by

$$
y(t)=\int \mathrm{H}(\mathrm{i} \omega) \mathrm{e}^{\mathrm{i} \omega t} \mathrm{dA}(\omega)
$$

with $\mathrm{H}(\mathrm{i} \omega)$ as admittance function of the filter adopted.

3. The spectral densities of the functions $x(t)$ and $y(t)$ are given by

$$
\operatorname{Sy}(\omega) / \operatorname{Sx}(\omega)=|H(i \omega)|^{2} \text {. }
$$

The structure is defined by complex wave numbers $\mathrm{r}_{\mathrm{i}}(\omega)$ with longitudinal and shear waves. The stationary waves are emitted from the source with complex amplitude $F\left(\omega, z_{0}\right)$, i.e., $z=z_{0}$. The wave superposition is given by

$$
\mathrm{w}_{\mathrm{i}}(\mathrm{t}, \mathrm{z})=\int \mathrm{e}^{-\mathrm{i} \omega \mathrm{t}} \mathrm{e}^{\mathrm{ir}(\omega \mathrm{z})} \mathrm{dF}\left(\omega, \mathrm{z}_{0}\right) .
$$

For wave interactions in inhomogeneities the following assumption is adopted: The inhomogeneity is touched by propagating waves. The response spectrum of the inhomogeneity is given by

$$
\mathrm{S}(\omega, 0)=\mathrm{S}\left(\omega, \mathrm{z}_{0}\right)|\mathrm{H}(\omega, 0)|^{2} \mathrm{e}^{-2 \operatorname{Im}[\mathrm{r}(\omega)]} \text {. }
$$

Response spectrum obtained is the basis for specification of physical parameters specified in virtual monitoring of thin-walled bridges, with adoption of the identification approach described below.

\section{Identification approach suggested}

Assumed is the system forcing given by white noise processes $e_{x}\left(t_{k}\right)$ and $e_{m}\left(t_{k}\right)$. Discrete time equivalents $\Delta \mathrm{x}\left(\mathrm{t}_{\mathrm{k}+1}\right)$ and $\Delta \mathrm{y}\left(\mathrm{t}_{\mathrm{k}+1}\right)$ are given by

$$
\Delta \mathrm{x}\left(\mathrm{t}_{\mathrm{k}+1}\right)=\mathrm{F} \Delta \mathrm{x}\left(\mathrm{t}_{\mathrm{k}}\right)+\mathrm{B} \mathrm{e}_{\mathrm{x}}\left(\mathrm{t}_{\mathrm{k}}\right),
$$




$$
\Delta y\left(t_{k+1}\right)=\left(G_{1}+G_{2}\right) A \Delta x\left(t_{k}\right)+e_{m}\left(t_{k}\right)
$$

where the state vector $\Delta \mathrm{x}$ contains the elements related to description of bridge system with possible stochastic properties and so do the system matrices F, B and G.

Covariance matrices for forcing are denoted $R_{x}\left(t_{i}\right)$ and $R_{x m}\left(t_{i}\right)$. The relation between covariance matrices $\mathrm{Y}\left(\mathrm{t}_{\mathrm{i}}\right)$ of the process $\mathrm{y}\left(\mathrm{t}_{\mathrm{k}}\right)$ and system matrices of the discrete time model is given by

$$
\mathrm{Y}_{\mathrm{k}}\left(\mathrm{t}_{\mathrm{i}}\right)=\mathrm{GF}_{\mathrm{k}-1} \mathrm{M}\left(\mathrm{t}_{\mathrm{i}}\right)
$$

with

$$
M\left(t_{i}\right)=F R_{x}\left(t_{i}\right) G^{T}+B R_{x m}\left(t_{i}\right) .
$$

The Hankel matrix established by adoption of covariance matrices $\mathrm{Y}_{\mathrm{k}}\left(\mathrm{t}_{\mathrm{i}}\right)$ is used in the identification and is suggested by following operations:

1. Form the Hankel matrix of the problem studied.

2. Compute the singular value decomposition of the Hankel matrix given by

$$
\mathrm{H}(\mathrm{p})=\mathrm{U}^{\circ} \mathrm{T}^{2} \mathrm{~V}^{\mathrm{T}} \text {, }
$$

where $\mathrm{U}$ and $\mathrm{V}$ are orthogonal matrices and $\mathrm{T}$ is diagonal and semidefinite matrix of singular values.

3. System matrices for discrete time space studied are given by

$$
\begin{gathered}
\mathrm{F}=\mathrm{T}^{-1} \mathrm{U}^{\mathrm{T}} \mathrm{H}(\mathrm{p}) \mathrm{V}, \\
\mathrm{M}=\mathrm{T} \mathrm{V}^{\mathrm{T}} \mathrm{E}_{\mathrm{n}}, \\
\mathrm{G}=\mathrm{E}_{\mathrm{n}} \mathrm{U}^{\circ} \mathrm{T},
\end{gathered}
$$

with

$$
E_{n}=\left[\begin{array}{lllll}
I_{n} & 0 & 0 & \ldots & 0
\end{array}\right] .
$$

4. Solve unsymmetric eigenvalue problem established from the ( $\mathrm{m} \times \mathrm{m}$ )-upper left submatrix of the ( $\mathrm{n} \times \mathrm{n})$-system matrix F.

5. Compute the modal parameters from eigenvalues and eigenvectors obtained.

6. Repeat operations from step 4 for increasing system submatrix dimension $\mathrm{m}$.

Before application of above identification approach the prefiltering of data is required. The type of filter applied depends on actual forcing conditions appearing.

\section{Ultimate response}

The Fourier integral transformation combined with the FETM-aproach ([8]) is adopted for the treatment of the problem.

Considered is the load $\mathrm{P}_{\mathrm{j}}(\mathrm{t})$ moving on thin-walled bridge studied. The load is assumed to be located in node $j(j=1,2,3, \ldots n)$ in time point $t$. The response in node $i$ is given by $X_{i}(t)(i$ 
$=1,2,3, \ldots \mathrm{m})$. The symbol $\mathrm{g}_{\mathrm{ij}}(\omega)$ specifies the spectral response function in node $\mathrm{i}$ due to input unit impulse $\mathrm{e}^{\mathrm{i} \omega \mathrm{t}}$. There holds

$$
X(t)=\int g(t) P(t) d t
$$

with vectors $\mathrm{X}(\mathrm{t})$ and $\mathrm{P}(\mathrm{t})$ of functions $\mathrm{X}_{\mathrm{i}}(\mathrm{t})$ and $\mathrm{P}_{\mathrm{i}}(\mathrm{t})$, respectively, and with $\mathrm{g}(\mathrm{t})$ as $(\mathrm{m} \mathrm{x} \mathrm{m})$ matrix of functions $g_{i j}(\omega)$. Generalized ultimate response is given by

$$
\operatorname{My}(\omega)=\mathrm{N}(\omega) \mathrm{Mp}(\omega) \text {, }
$$

where $N(\omega)$ is the complex transfer function of the bridge and $M_{Y}(\omega)$ is the ultimate response transform of the forcing function $\mathrm{M}_{\mathrm{P}}(\omega)$. The complex function of structural response $\mathrm{N}(\omega)$ defines spectral characteristics of the bridge under adoption of above identification approach and specifies simultaneously amplitude and phase shift of the response related to harmonic components of ultimate forcing spectrum initiated.

The model assumed allows the simulation of all structural parameters appearing in linear and nonlinear ultimate behaviour analysis. In updated Lagrangian formulation of motion the major geometric nonlinearities are to be implemented into coordinate transformations of the microelement mesh used. The effects of physical nonlinearities are analysed on the level of macroelement mesh. The mesh works with dynamic variability of micro- and macroelement sizes adopted.

\section{Structural multi-optimization}

Multi-optimization is adopted as a selection of testing parameters allowing minimum weight or fully stressed approach in virtual monitoring of thin-walled bridges. The selection of testing parameters is subjected to following types of constraints:

- geometric constraints - minimum and maximum areas, dimensions and rigidities of thin-walled members adopted,

- stress constraints - maximum allowable stress,

- displacement constraints - minimum and maximum deformations, rotations and displacements,

- resonance, stability and fatigue ultimate limits.

Such items specify the regional constraints and are applied for all loads occurring. They are represented by constraint hypersurfaces. Stress, deformations and resonance, stability or fatigue ultimate limits are nonlinear functions of the testing variables adopted. The constraint hypersurfaces are nonlinear functions of such variables. If virtual testing point lies above the constraint surfaces then stress or displacements in regional constraints are within specified limits. The contact of the constant-weight hypersurface with the constraint hypersurfaces adopted is the point for optimal multi-functioning in the minimum weight design.

When constraints are imposed only on the stress, an iterative procedure is used to re-design the multi-functioning of thin-walled structure so that each element reaches limiting stress under at least one of the load conditions assumed. Such design is described as a fully stressed design. The design variables for fully stressed design converge to a vertex of $n$ hypersurfaces representing the $\mathrm{n}$ constraints on the stress. 
In many synthesis methods the solution efficiency is highly dependent on the number of variables being multi-optimized simultaneously in order to obtain the multi-functioning of all thin-walled members. While the optimal design is usually improved by considering geometric variables, the objective functions for minimum-weight or fully stressed designs are often not sensitive to changes of such variables near the optimum.

The multi-optimization is stated as follows: Find the geometric testing variables $\mathrm{Y}$ and the cross-sectional design variables $\mathrm{X}$ or $\mathrm{Z}$ (as other types of variables) such, that holds:

objective functions

geometric constraints

$$
\mathrm{W}=\mathrm{f}(\mathrm{X}, \mathrm{Y}, \mathrm{Z}) \rightarrow \min ,
$$$$
\mathrm{X}^{\mathrm{L}} \leq \mathrm{X} \leq \mathrm{X}^{\mathrm{U}}
$$$$
\mathrm{Y}^{\mathrm{L}} \leq \mathrm{Y} \leq \mathrm{Y}^{\mathrm{U}}
$$$$
\mathrm{Z}^{\mathrm{L}} \leq \mathrm{Z} \leq \mathrm{Z}^{\mathrm{U}}
$$

stress constraints

$$
\sigma^{\mathrm{L}} \leq \sigma \leq \sigma^{\mathrm{U}}
$$

displacement constraints

$$
\mathrm{r}^{\mathrm{L}} \leq \mathrm{r} \leq \mathrm{r}^{\mathrm{U}}
$$

resonance, stability and fatigue constraints $\gamma^{\mathrm{L}} \leq \gamma \leq \gamma^{\mathrm{U}}$,

where the superscripts $\mathrm{L}$ und $\mathrm{U}$ denote the lower and upper bounds, respectively. The symbols $\sigma, \mathrm{r}$ and $\gamma$ are the vectors of stress, displacements and resonance, stability or fatigue limits adopted. Such limits are implicit functions of testing variables adopted.

In order to multi-optimize simultaneously all above variables one of available nonlinear techniques is to be applied. A possible two level solution procedure is given by:

1. assumption of an initial structural geometry,

2. optimization of all testing variables for given geometry by satisfaction of Eqs. (17) (23),

3. modification of the variables,

4. repeating of the steps 2 and 3 until the results of virtual monitoring are obtained.

The number of testing variables is to be reduced by stating all above parameters in the terms of a small number of independent variables. In order to reduce the number of candidate testing variables is significant to use a coarse grid in the space of geometric variables, so that only a small number of $\mathrm{X}, \mathrm{Y}$ or $\mathrm{Z}$ values is to be considered. This is justified in case where objective function (the minimum weight design or the fully stressed design) is not sensitive to the changes in testing variables near the optimum. In order to optimize the $\mathrm{X}, \mathrm{Y}$ and $\mathrm{Z}$ variables, one of known unconstrained minimization techniques (see Refs. [2], [3], [4] or [5]) is to be used. 


\section{Evolution strategies}

Evolution strategies appear as effective tools for nonlinear multi-functioning analysis in virtual monitoring and apply the principles of evolution in biology for the treatment of technical problems. The principle of such methods is given by

$$
X^{(k+1)}= \begin{cases}X^{(k)}+p^{k}, & \text { for } z\left(x^{(k)}+p^{(k)}\right)<z\left(x^{(k)}\right) \\ X^{(k)}, & \text { for } z\left(x^{(k)}+p^{(k)}\right) \geq z\left(x^{(k)}\right)\end{cases}
$$

where $X^{(k+1)}$ is the multi-functioning optimization vector for the step $k+1, x^{(k)}$ is the corresponding vector of testing variables for the step $\mathrm{k}, \mathrm{p}^{(\mathrm{k})}$ is the random vector for the step $\mathrm{k}$ and $\mathrm{z}$ is the value of the objective function adopted. The laws of evolution in biology specify the selection of better individuals (parents or ancestors) and their installation as parents of the new generation. The worser of both is eliminated.

So-called (1+1)-evolution strategy (see Refs. [6] and [7]) adopts the analogy with evolution in biology for the mutation of the decisive factor for the testing variables optimized. The checking of obtained values specifies the selection of better approximating testing parameters and their utilization as starting values for the next iteration step assumed. Such concept is defined by following operations:

1. By application of the allowable values of the vector $\mathrm{x}^{(\mathrm{k})}$ and of the random vector $\mathrm{p}^{(\mathrm{k})}$ there will be specified the new optimization vector $\mathrm{x}^{(\mathrm{k}+1)}$ given by

$$
\mathrm{x}^{(\mathrm{k}+1)}=\mathrm{x}^{(\mathrm{k})}+\mathrm{p}^{(\mathrm{k})} \text {. }
$$

The random vector $\mathrm{p}^{(\mathrm{k})}$ performs the function of mutation.

2. If the optimization vector $\mathrm{x}^{(\mathrm{k}+1)}$ is allowed, there are calculated the values of objective function $\mathrm{z}\left(\mathrm{x}^{(\mathrm{k}+1)}\right)$ with subsequent selective part of the solution. New optimization vector $\mathrm{x}^{(\mathrm{k}+1)}$ is accepted only if it has better approximation to the optimum compared with all foregoing cases. Iteration scheme for such optimization procedure is given by Eq. (25). For specification of the vector $\mathrm{p}^{(\mathrm{k})}$ the density and deviation of each of its components is to be specified.

\section{Numerical and experimental assessment}

The aeroelastic response of slender bridge models was studied in the wind tunnel in order to obtain the information on ultimate aeroelastic behaviour and the significance of the windscreen barriers adopted on the long-span bridge in Svrcinovec, Slovakia.

Special moment transducer (Fig. 1) was developed for experimental assessment in the wind tunnel of the Institute of Construction and Architecture, Slovak Academy of Sciences in Bratislava. The transducer was calibrated regarding the outputs of the measurement facilities adopted. For three horizontal moment axes there were established the constant stiffness coefficients given by $1364 \mathrm{Nm} / \mathrm{rad}$. For torques the corresponding stiffness coefficients were given by $251 \mathrm{Nm} / \mathrm{rad}$. No deviations from the linear behaviour of transducer in scope of maximal rotations 0.008 rad were registered. The modal inertia for flexural modes of 
transducer vibration is given by $0.0004 \mathrm{kgm}^{2}$. The transducer is equipped with diagonal rods made of steel wire with diameter $2 \mathrm{~mm}$ and being anchored in the base plate. Prestressing of the rods allows there to vary the stiffness and damping parameters of the experimental set up adopted in accordance with the model affinity with actual structure.

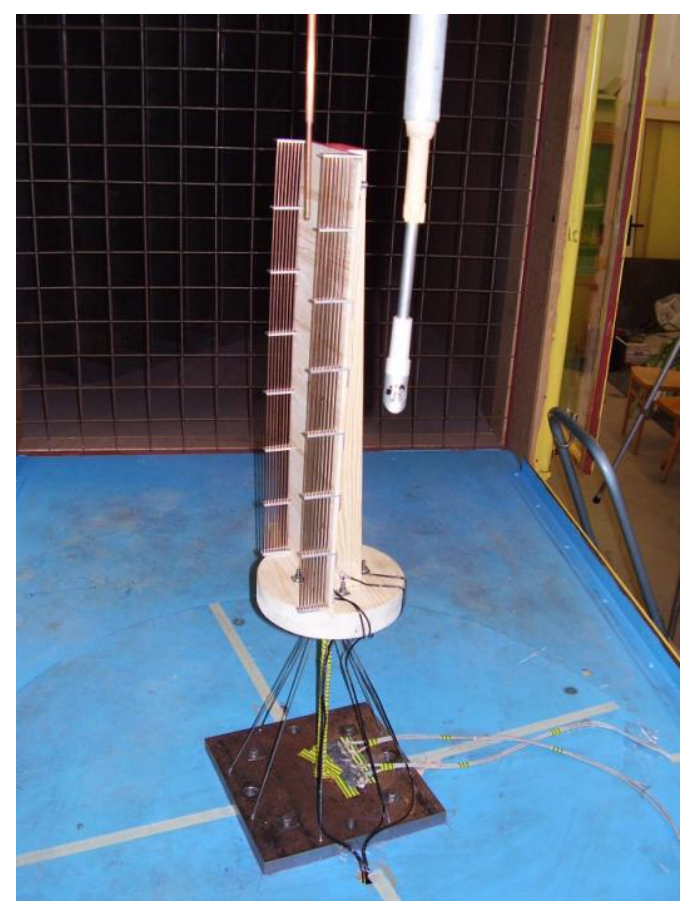

Figure 1: View of the experimental set-up in the wind tunnel

Transducer and bridge model with wind-barriers were located as experimental set-up in the wind tunnel (see Fig. 1). Adopted was the working section of the tunnel with cross-sectional dimensions $1200 \times 1200 \mathrm{~mm}$, where the experimental set-up represented $3 \%$ of total crosssectional area.

Two configurations of the model simulating the bridge, without and with wind-screen barriers, were studied. The top of the models was provided with flat plywood disc. The massive model wood base plate was connected with a dynamic flexure transducer being the main source of flexibility of the model set-up. In the model flow-exposed part there appeared secondary flexibility effects. The model was equipped with exchangeable wind-screen barriers simulating the actual bridge structure. Experimental set-up adopted in the wind tunnel is shown in Fig. 1. Experimental configurations of the bridge cross-section studied are plotted in Figs. 2 - 4.

During the wind tunnel tests the air speed was set in many steps in scope $0-35 \mathrm{~m} / \mathrm{sec}$. Some along-wind and cross-wind flexural deflections and accelerations obtained for both model configurations studied are plotted in Figs. 5 - 7. Studied were the influences only of the laminar air flow in the wind tunnel. The model was tuned by prestressing steel rods in order to obtain static, stiffness and damping parameters of actual bridge structure studied. The evaluation of the results obtained has submitted the decrease of non-reduced response at bridge attitudes $+15^{\circ}$ compared with wind direction, with dominant influence of galloping. 


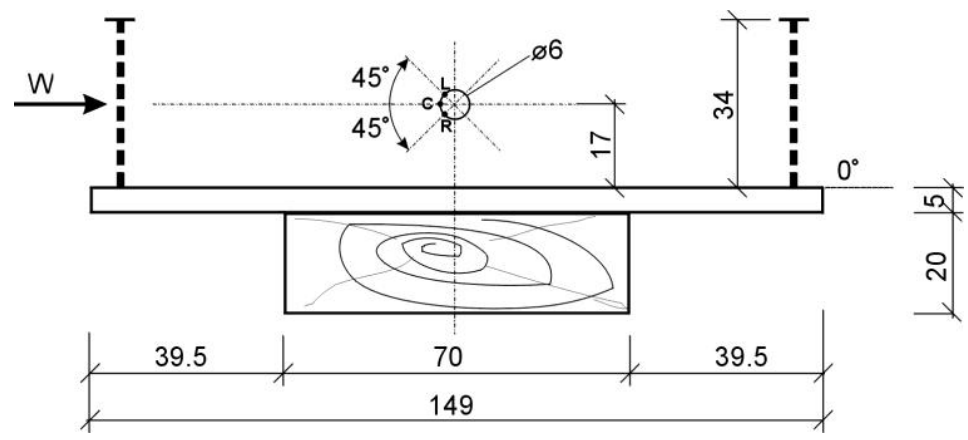

Figure 2: Cross-section with wind-screens and the location of the pressure gauge for the model attitude $0^{\circ}$ compared with wind direction

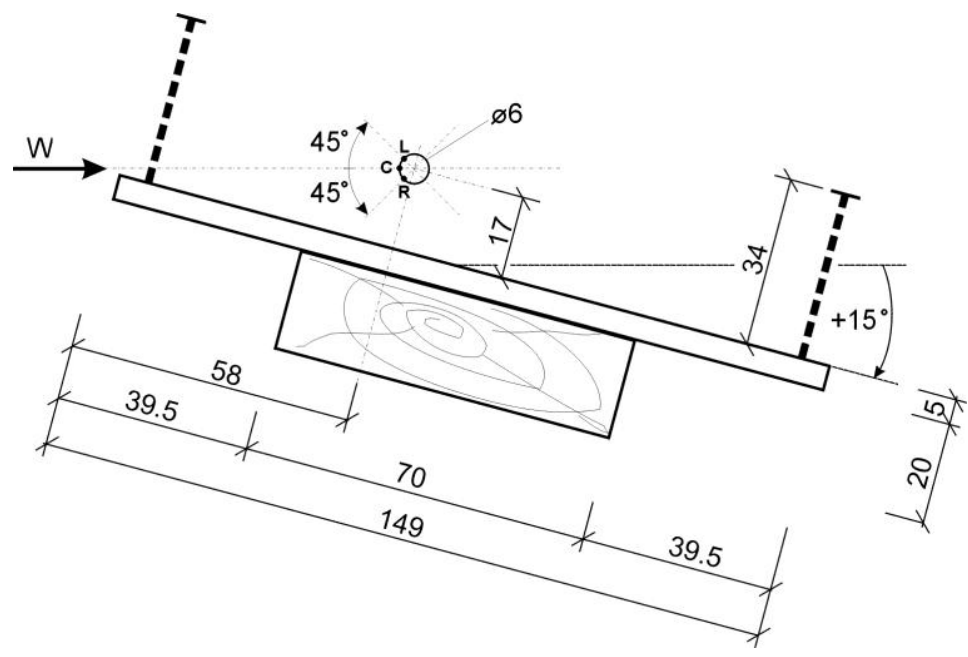

Figure 3: Cross-section with wind-screens and the location of the pressure gauge for the model attitude $15^{\circ}$ cmpared with wind direction

The oscillations observed can be explained by some possible mechanisms. There may be eddies shed over the top plate, vortices shed parallel to the horizontal axis or vortex shedding in combination with galloping and flutter, the last one especially for the model configuration with wind-screen barriers adopted.

Above theoretical analysis was used for the numerical treatment of the problem with following experimental assessment in te arodynamic tunel. The evaluation of some numerical and experimental results obtained is submitted in Tables 1 and 2. 


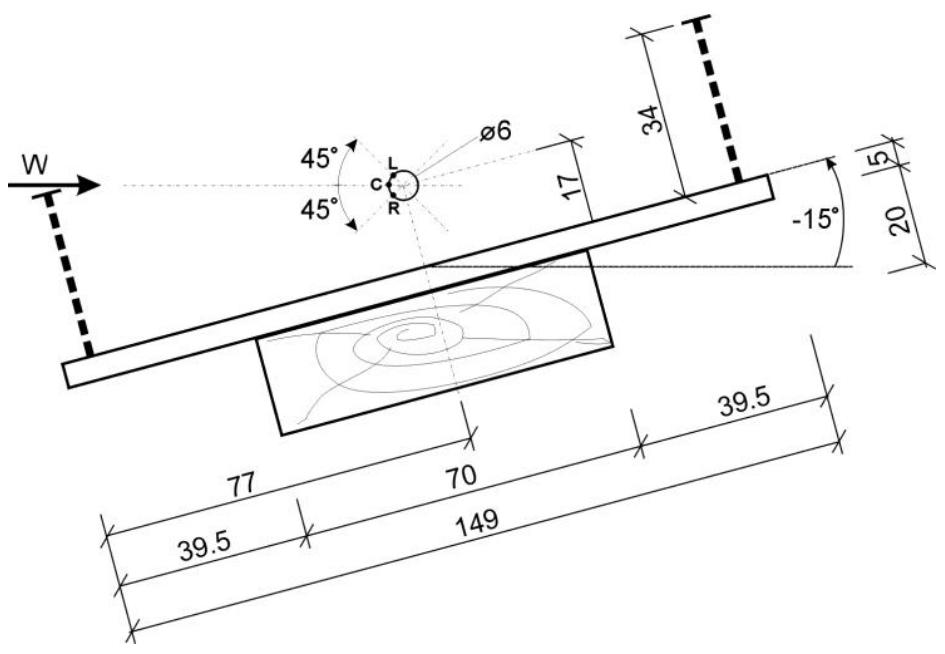

Figure 4 Cross-section wind-screens and the location of the pressure gauge for the attitude $15^{\circ}$ cmpared with wind direction

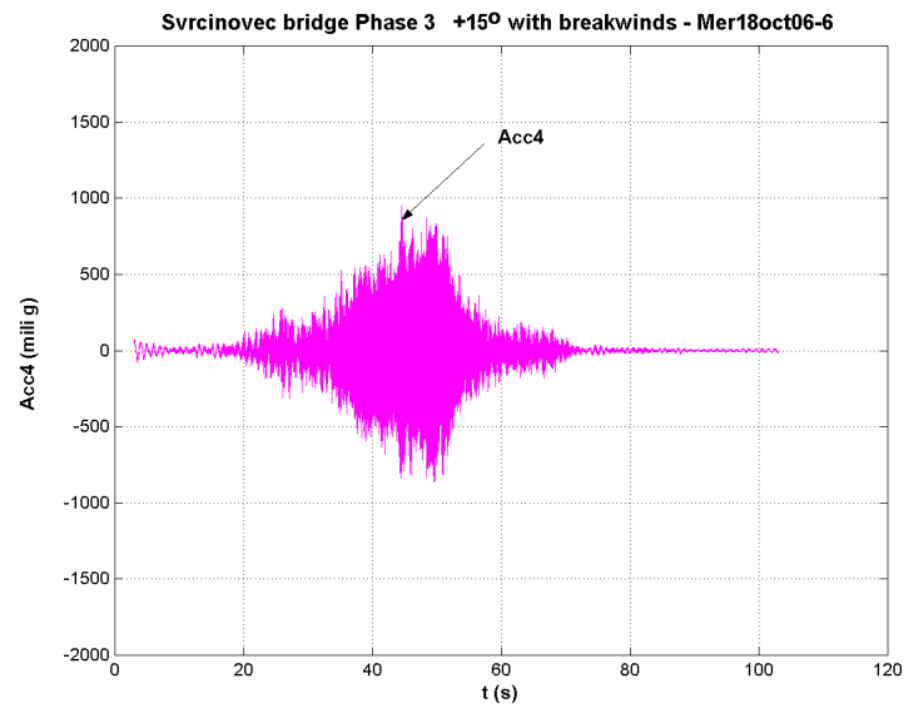

Figure 5: Acceleration of vertical displacement vs time in gauge of the model set-up

\section{Conclusion}

Some approaches for virtual testing, multi-functioning and multi-optimization of slender bridges made of thin-walled members were submitted. Focused were approaches on the basis of evolution strategies and their adoption in the behaviour control of such bridges.

The analysis tools used in this paper are the methods of transient Dynamics. Such methods allow the study of resulting ultimate aeroelastic response of the bridges equipped with windscreen barriers. Numerically and experimentally was stated the significance of the windscreens in improving of aeroelastic stability and traffic reliability of the bridges studied. 


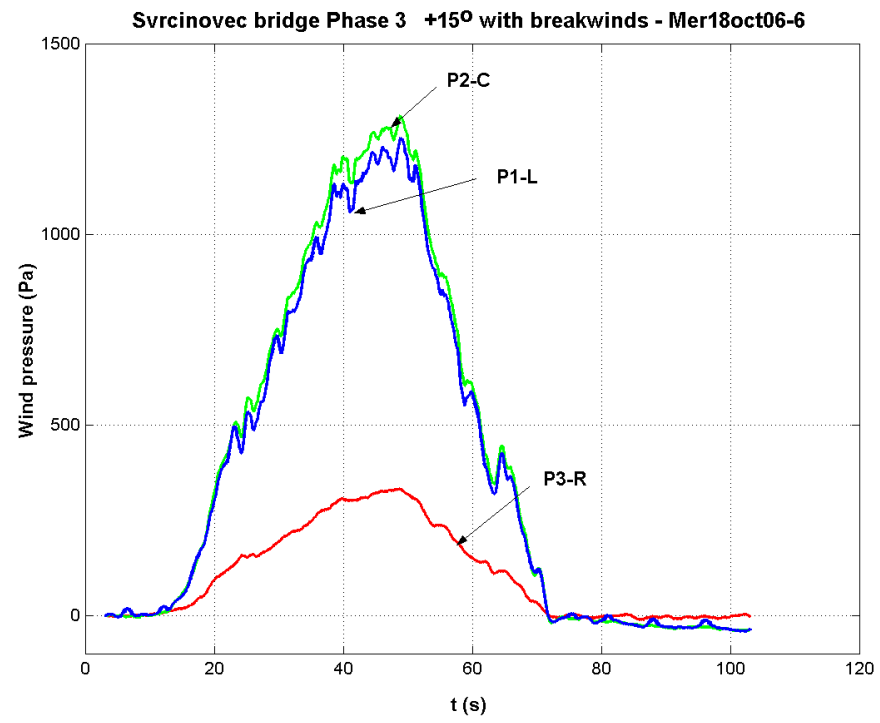

Figure 6: Wind pressure vs time on the roadway of the model set-up

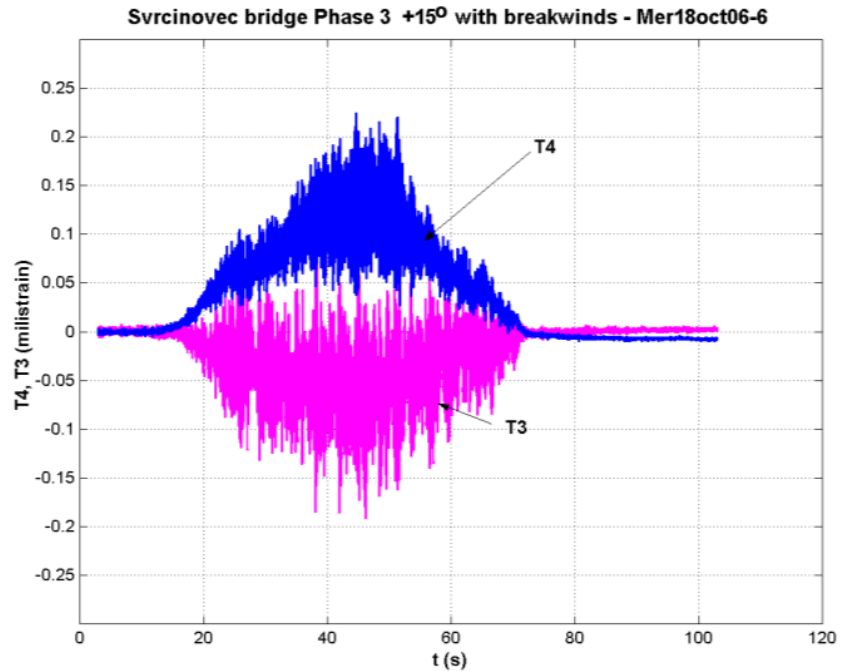

Figure 7: Amplitude of vertical displacement vs time in gauge of the model set-up

Table 1: Model with wind-screens - absolute values of extreme accelerations and strains

\begin{tabular}{|l|l|l|l|l|l|l|l|l|l|}
\hline Test & $\begin{array}{l}\text { vmax } \\
(\mathrm{m} / \mathrm{s})\end{array}$ & $\begin{array}{l}\mathrm{a} 1 \mathrm{max} \\
(\mathrm{mg})\end{array}$ & $\begin{array}{l}\mathrm{a} 2 \mathrm{max} \\
(\mathrm{mg})\end{array}$ & $\begin{array}{l}\mathrm{a} 3 \mathrm{max} \\
(\mathrm{mg})\end{array}$ & $\begin{array}{l}\mathrm{a} 4 \mathrm{max} \\
(\mathrm{mg})\end{array}$ & $\begin{array}{l}\text { T3max } \\
\text { cross- } \\
\text { wind } \\
(\mathrm{mstrain})\end{array}$ & $\begin{array}{l}\mathrm{T} 4 \mathrm{max} \\
\text { along- } \\
\text { wind } \\
(\mathrm{mstrain})\end{array}$ & $\begin{array}{l}\mathrm{T} 3 \mathrm{~m}, \mathrm{max} \\
(1 \mathrm{~s}) \\
(\mathrm{mstrain})\end{array}$ & $\begin{array}{l}\mathrm{T} 4 \mathrm{~m}, \mathrm{max} \\
(1 \mathrm{~s}) \\
(\mathrm{mstrain})\end{array}$ \\
\hline $\begin{array}{l}3-3 \\
0^{\circ}\end{array}$ & 33 & 52.352 & $\begin{array}{l}376.243 \\
23.8 \mathrm{~Hz}\end{array}$ & - & $\begin{array}{l}340.686 \\
21.19 \mathrm{~Hz}\end{array}$ & 0.1054 & 0.2089 & 0.0552 & 0.1481 \\
\hline $\begin{array}{l}3-4 \\
0^{\circ}\end{array}$ & 32.2 & 110.964 & 595.785 & 742.026 & - & 0.1427 & 0.2060 & 0.0620 & 0.1449 \\
\hline $\begin{array}{l}3-5 \\
+15^{\circ}\end{array}$ & 33 & 105.565 & 778.712 & 852.747 & - & 0.1759 & 0.2215 & 0.0695 & 0.1341 \\
\hline $3-6$ & 32.6 & 62.601 & 415.026 & - & 953.238 & 0.1922 & 0.2243 & 0.0736 & 0.1315 \\
\hline
\end{tabular}




\begin{tabular}{|l|l|l|l|l|l|l|l|l|l|}
\hline$+15^{\circ}$ & & & $23.66 \mathrm{~Hz}$ & & $21.8 \mathrm{~Hz}$ & & & & \\
\hline $3-1$ & 32 & $1581.5 ?$ & $1377.5 ?$ & 1325.0 & - & 0.2393 & 0.1637 & 0.1714 & 0.1065 \\
$-15^{\circ}$ & & & & & & & & & \\
\hline $3-2$ & 32.4 & 68.295 & 238.720 & - & 270.515 & 0.2293 & 0.1268 & 0.1754 & 0.0800 \\
$-15^{\circ}$ & & & $23.7 \mathrm{~Hz}$ & & $\begin{array}{l}20.32 \mathrm{~Hz} \\
26.6 \mathrm{~Hz}\end{array}$ & & & & \\
\hline
\end{tabular}

Table 2: Model with wind-screens-absolute values of extreme wind pressure in the roadway

\begin{tabular}{|l|l|l|l|l|}
\hline Test & $\begin{array}{l}\text { vmax } \\
(\mathrm{m} / \mathrm{s})\end{array}$ & $\begin{array}{l}\text { P1Lmax } \\
(\mathrm{Pa})\end{array}$ & $\begin{array}{l}\text { P2Cmax } \\
(\mathrm{Pa})\end{array}$ & $\begin{array}{l}\text { P3Rmax } \\
(\mathrm{Pa})\end{array}$ \\
\hline $\begin{array}{l}3-3 \\
0^{\circ}\end{array}$ & 33 & 966.640 & 838.661 & 265.078 \\
\hline $\begin{array}{l}3-4 \\
0^{\circ}\end{array}$ & 32.2 & 985.241 & 821.996 & 258.422 \\
\hline $\begin{array}{l}3-5 \\
+15^{\circ}\end{array}$ & 33 & 1195.5 & 1279.7 & 332.424 \\
\hline $\begin{array}{l}3-6 \\
+15^{\circ}\end{array}$ & 32.6 & 1252.5 & 1311.4 & 333.440 \\
\hline $\begin{array}{l}3-1 \\
-15^{\circ}\end{array}$ & 32 & 868.022 & 641.429 & 235.741 \\
\hline $\begin{array}{l}3-2 \\
-15^{\circ}\end{array}$ & 32.4 & 749.207 & 486.781 & 209.342 \\
\hline
\end{tabular}

\section{Acknowledgements}

The authors are indebted to Slovak Grant Agencies VEGA and APVV for supporting and sponsoring the scientific activities reported.

\section{References}

[1] Da Vinci, L. Manuscript RL 19115v; K/P 114r located in the Royal Library, Windsor Castle, Windsor, England, ca. 1500

[2] Razani, R. (1965). Behaviour of fully stressed design of structures and its relationship to minimum-weight design. Journal Amer. Inst. Aeron. Astron., 3, pp. 2262-2268.

[3] Fox, R. L. (1971). Optimization Methods for Engineering Design. Addison-Wesley Publishing Group, Reading., Mass.

[4] Kirsch, U. (1982). Synthesis of structural geometry using approximate concepts. Comp. Struct., 15 , pp. 103-111

[5] Schmit, L.A., and Miura, H. (1975). A new structural analysis/synthesis capability - access 1'. In Proc. AIAA/ASME/SAE, 16-th Conference, Denver, Col., 1975, 307-315

[6] Tesar, A. (1985). Synthesis in optimisation of shell bridge structures. Building Research Journal, 35, 812-824

[7] Rechenberg, J. (1977). Evolutionsstrategie. Reihe Problemata 15, F. Frommann Verlag, Stuttgart - Bad Cannstadt 